SEÇÃO: ARTIGOS

\title{
A EDUCAÇÃO DE JOVENS E ADULTOS NO CONTEXTO DA FORMAÇÃO DE PROFESSORES DE BIOLOGIA
}

\author{
Rones de Deus Paranhos ${ }^{1}$, Lucas Martins de Avelar ${ }^{2}$ \\ Cristina da Costa Krewer Mascioli ${ }^{3}$, Simone Sendin Moreira Guimarães ${ }^{4}$
}

\section{RESUMO}

O artigo relata o processo de criação e implementação de uma disciplina que trata da modalidade Educação de Jovens e Adultos (EJA), oferecida em um curso de Ciências Biológicas - Licenciatura. O relato toma como ponto de partida a demanda de formar professores de Biologia para a EJA e, a partir disso, apresenta a criação de uma disciplina de EJA que se deu no conjunto de atividades ligadas à reformulação do Projeto Pedagógico de Curso (PPC). Quanto ao processo de implementação, são destacados as unidades didáticas e os objetivos; o processo de avaliação; e a percepção dos estudantes sobre as atividades desenvolvidas durante a disciplina. Fica sinalizada a necessidade de a EJA integrar parte da formação de professores de Biologia e espera-se que o relato motive o desenvolvimento de outras experiências.

Palavras-chave: Formação docente. Educação em Ciências. Componente curricular. Educação de Jovens e Adultos.

\section{Como citar este documento - ABNT}

PARANHOS, Rones de Deus; AVELAR, Lucas Martins de; MASCIOLI, Cristina da Costa Krewer; GUIMARÃES, Simone Sendin Moreira. A educação de jovens e adultos no contexto da formação de professores de Biologia. Revista Docência do Ensino Superior, Belo Horizonte, v. 10, e020389, p. 1-19, 2020. DOI: https://doi.org/10.35699/2237-5864.2020.20389.

Recebido em: 07/05/2020 Aprovado em: 04/06/2020 Publicado em: 15/09/2020

\footnotetext{
${ }^{1}$ Universidade Federal de Goiás (UFG), Goiânia, GO, Brasil. ORCID: https://orcid.org/0000-0002-2661-1235. E-mail: paranhos@ufg.br ${ }^{2}$ Universidade Federal de Goiás (UFG), Goiânia, GO, Brasil. ORCID: https://orcid.org/0000-0003-1948-903X. E-mail: lucasmavelar@gmail.com ${ }^{3}$ Universidade Federal de Goiás (UFG), Goiânia, GO, Brasil. ORCID: https://orcid.org/0000-0003-4976-9470. E-mail: criskrewer@ufg.br ${ }^{4}$ Universidade Federal de Goiás (UFG), Goiânia, GO, Brasil.

ORCID: https://orcid.org/0000-0002-6559-2591. E-mail: sisendin@ufg.br
} 


\section{EDUCACIÓN JUVENIL Y ADULTA EN EL CONTEXTO DE LA FORMACIÓN DE PROFESORES DE BIOLOGÍA}

\section{RESUMEN}

El artículo informa sobre el proceso de creación e implementación de una asignatura que se ocupa de la Educación de Jóvenes y Adultos (EJA), ofrecida a una carrera de Ciencias Biológicas - Licenciatura. El informe toma como punto de partida la demanda de formar docentes de Biología para EJA y, a partir de ahí, presenta la creación de una asignatura EJA que tuvo lugar en el conjunto de actividades relacionadas con la reformulación del Proyecto Pedagógico de la Carrera (PPC). En cuanto al proceso de implementación, se destacan las unidades didácticas y objetivas; El proceso de evaluación y la percepción de los estudiantes sobre las actividades desarrolladas durante la asignatura. Se señala la necesidad de que EJA tome parte de la formación de profesores de Biología y se espera que este informe motive el desarrollo de otras experiencias.

Palabras clave: Formación de los docentes. Educación en Ciencias. Componente curricular. Educación de Jóvenes y Adultos.

\section{YOUTH AND ADULT EDUCATION IN THE CONTEXT OF BIOLOGY TEACHER TRAINING}

\section{ABSTRACT}

The article reports the process of creating and implementing a discipline of Youth and Adult Education (EJA), offered in the Degree in Biological Sciences course. The report takes as a starting point the demand to form Biology teachers for EJA and, from that, presents the creation of an EJA discipline. The creation took place during the set of activities related to the reformulation of the Pedagogical Course Project. As for the implementation process, the didactic units and objectives are highlighted; the evaluation process; and the students' perception of the activities developed during the discipline. It signaled the need for the EJA part of the training of Biology teachers and it is expected that the report motivate the development of other experiences.

Keywords: Teacher education. Science Education. Curricular component. Youth and Adult Education. 


\section{INTRODUÇÃO}

A Educação de Jovens e Adultos (EJA) é destinada aos maiores de 15 anos de idade da população brasileira que não iniciaram e/ou concluíram a educação básica (Ensino Fundamental e Médio). Há estudos que indicam um quantitativo expressivo de pessoas que constituiriam o público da modalidade. De acordo Alves et al. (2014), 64\% dos brasileiros da faixa etária destacada anteriormente não concluíram a educação básica; Haddad e Siqueira (2016) apontam que 13,1 milhões de pessoas não são alfabetizadas.

A Lei de Diretrizes e Bases da Educação Nacional (LDB - Lei no 9.394/96) demarca a EJA como uma modalidade da educação básica, constituindo-a, portanto, um campo para o desenvolvimento das práticas pedagógicas do professor de Biologia. Contudo, após 24 anos da promulgação da LDB, a discussão da EJA ainda é uma demanda a ser posta na esteira da formação de professores no Brasil.

Mais do que definir a EJA a partir dos marcos regimentais e do quantitativo de público que desenham a demanda da modalidade, é necessário compreendê-la a partir dos processos que engendraram a necessidade histórica de escolarizar adolescentes, jovens, adultos e idosos, tendo no horizonte a perspectiva da educação como direito. O que significa pautar e defender essa perspectiva? Num primeiro momento, nos vem a questão do acesso à educação escolar e isso se trata de um elemento necessário. É importante que as escolas de EJA estejam próximas ao seu público demandante. É urgente que as secretarias de Educação (estadual e municipal) cumpram o papel de realizar a chamada pública ${ }^{5}$, conforme os marcos da LDB/1996. É premente a demanda de se pensar os espaços escolares que sejam atinentes à identidade do público da EJA.

Para além do acesso à escola, é necessário marcar o traço do direito de aprender os conhecimentos sistematizados (artístico, científico e filosófico) construídos pela atividade humana, que possibilitam leituras da realidade livres da dependência do referencial empírico imediato (conceitos espontâneos). A escola é o espaço de socialização do saber sistematizado (SAVIANI, 2013) e, para a classe trabalhadora, representa um dos poucos lugares de acesso a esse saber. Portanto, não cabe privar os estudantes da possibilidade de se desenvolverem pela apropriação do conhecimento científico, destinando a eles uma formação aligeirada, mercantil, assistencialista e compensatória.

\footnotetext{
${ }^{5}$ A chamada pública está prevista no Art. 5o, §1으, Inciso II da Lei no 9.394/96 (LDB). Trata-se de um mecanismo para informar a população sobre a existência de escolas de EJA e os períodos de realização de matrícula. A chamada pública pode ser realizada pelos governos da esfera federal, estadual e municipal via campanhas publicitárias (televisiva, rádios), carros de som etc. Escolas de EJA são fechadas com a justificativa de não haver demanda de alunos, mas o Estado não implementa a lógica de ir até o público da modalidade via a realização da chamada pública (PAIVA, 2019).
} 
As Conferências Internacionais de Educação de Adultos (CONFINTEA) têm apontado desde 1949 a necessidade de as universidades formarem professores para trabalhar com a educação de adultos (PARANHOS; FIRMINO, 2013). Esses autores ainda destacam que a demanda também está marcada em documentos oficiais como: a) LDB/1996 (BRASIL, 1996); b) a Resolução no 1/2002 do Conselho Nacional de Educação - Conselho Pleno (BRASIL, 2002); c) Parecer no 11/2000 do Conselho Nacional de Educação - Câmara de Educação Básica (BRASIL, 2000). Atualmente, tem-se ainda a Diretriz Nacional Curricular para a Formação de Professores (BRASIL, 2019), mas o documento vigente à época da formulação da disciplina, ora relatada, foi a diretriz contida em Brasil (2015).

Os marcos regimentais não têm garantido a inserção da EJA nos cursos de formação inicial de professores, e podemos afirmar que as pesquisas e os movimentos sociais, há mais de vinte anos, têm explicitado a demanda da EJA nas licenciaturas. Como exemplo, o estudo de Soares (2005) apontou que 1,59\% dos cursos de Pedagogia oferecia, à época do levantamento, habilitação para a modalidade da Educação de Jovens e Adultos. Em outra investigação, esse autor indicou que no Brasil havia 175 mil professores de EJA. Estes, entretanto, não receberam uma formação que considerasse a modalidade e suas demandas (SOARES, 2006).

Os relatórios-síntese do Encontro Nacional de Educação de Jovens e Adultos (ENEJA) ${ }^{6}$ indicam, desde o ano de 1999, a demanda de alargar a compreensão sobre o que significa escolarizar jovens, adultos e idosos e destacam ainda a necessidade de os cursos de licenciatura acamparem a discussão da EJA $^{7}$ (PARANHOS; FIRMINO, 2013). Outros estudiosos, como Ventura e Bomfim (2015), afirmam que a EJA não tem lugar de destaque em propostas curriculares de formação de professores, bem como nas pesquisas sobre o tema. Ainda para essas autoras, o que se observa nos cursos de formação de professores é o predomínio de "[...] formulações que desprezam as relações entre formação humana, conhecimento e classe social e deixam de considerar que os indivíduos a serem educados na EJA são formados histórica e socialmente" (VENTURA; BOMFIM, 2015, p. 221). As pesquisas de Mota (2019) e Viñal-Jr. e Miranda (2019) também apresentam a demanda dos cursos de licenciatura acamparem a discussão da EJA para a formação de professores. No campo da pesquisa, os estudos de Paranhos (2017), Paranhos e Carneiro (2019) e Pereira, Oliveira e

\footnotetext{
6 “No Brasil há um movimento que articula pessoas de diferentes regiões brasileiras e dá corpo ao Fórum Brasileiro de Educação de Jovens e Adultos. Nesse fórum e pelas reuniões realizadas nos Encontros Nacionais de Educação de Jovens e Adultos (ENEJA19) se materializa a prática de socializar informações; trocar experiências; estabelecer pautas de lutas nos contextos municipais, estaduais e nacional; além de apontar indicativos para formulação de políticas públicas de EJA nas esferas municipal, estadual e federal" (PARANHOS, 2017, p. 18).

${ }^{7}$ Para ter acesso aos Relatórios Síntese do Encontro Nacional de Educação de Jovens e Adultos acesse o link: http://forumeja.org.br/brasil.
} 
Ferreira (2019) apontam que ainda são tímidas as iniciativas de pesquisas que consideram o objeto formação de professores para a EJA.

Uma das vias para alargar a compreensão da Educação de Jovens e Adultos e sua necessidade histórica, bem como campo pedagógico do exercício profissional do professor, é inseri-la nas licenciaturas. De acordo com Ventura (2012, p. 79), isso superaria desafios ligados a processos de improvisação de práticas pedagógicas destinadas à Educação de Jovens e Adultos, tendo em vista "[...] qualificar os quadros docentes para um trabalho que respeite as especificidades do público jovem e adulto, no que concerne à elaboração de propostas pedagógicas que contemplem tempos e espaços de aprendizagens deste público".

Especificamente para a formação de professores, Paranhos (2009) indica que as Diretrizes Curriculares para os cursos de Licenciatura em Ciências Biológicas não consideram as especificidades da EJA e nem um perfil formativo do professor de Biologia para trabalhar nessa modalidade da educação básica. Por outro lado, a Resolução do Conselho Nacional de Educação no 2/2015, que estabelece as diretrizes para formação inicial e continuada de professores, reconhece em seu Art. 2ำ uma formação atinente à Educação de Jovens e Adultos (BRASIL, 2015).

Paranhos e Firmino (2013) realizaram um levantamento dos cursos de Ciências Biológicas Licenciatura em universidades públicas federais das capitais dos estados brasileiros e constataram, pela análise dos Projetos Pedagógicos de Curso (PPC), que apenas duas universidades da Região Sul possuíam disciplinas (optativas) que abarcavam a discussão da Educação de Jovens e Adultos. Num contexto mais específico, Murça et al. (2013) analisaram os PPC de nove cursos de Licenciatura em Ciências Biológicas oferecidos por instituições públicas de Goiás (federais e estaduais) e constataram que apenas uma instituição oferecia uma disciplina específica (optativa) para EJA. A atualização desses dados está expressa no Quadro 1 e indica um avanço quanto ao número de componentes curriculares de EJA oferecidos aos cursos como disciplina obrigatória. 


\begin{tabular}{|c|c|c|c|c|c|}
\hline Instituto de Educação Superior & Campus & $\begin{array}{l}\text { PPC/MC } \\
\text { Ano }\end{array}$ & Componente Curricular & $\mathrm{CH}$ & Natureza \\
\hline \multirow{2}{*}{$\begin{array}{c}\text { Instituto Federal de Educação, Ciência } \\
\text { e Tecnologia de Goiás (IFG) }\end{array}$} & Águas Lindas & 2018 & Educação de Jovens e Adultos & 54 & Obrigatória \\
\hline & Formosa & 2018 & Educação de Jovens e Adultos & 60 & Obrigatória \\
\hline \multirow{5}{*}{$\begin{array}{l}\text { Instituto Federal de Educação, Ciência } \\
\text { e Tecnologia Goiano } \\
\text { (IFGoiano) }\end{array}$} & Catalão* & ND & --- & --- & --- \\
\hline & Ceres & 2017 & Educação de Jovens e Adultos & 36 & Obrigatória \\
\hline & Posse & 2020 & Educação de Jovens e Adultos & 38 & Obrigatória \\
\hline & Rio Verde & 2013 & $\mathrm{NP}$ & --- & --- \\
\hline & Urutaí & 2017 & Educação de Jovens e Adultos & 68 & Obrigatória \\
\hline \multirow{6}{*}{$\begin{array}{l}\text { Universidade Estadual de Goiás } \\
\text { (UEG) }\end{array}$} & Anápolis & 2016 & NP & --- & --- \\
\hline & Iporá & 2015 & NP & --- & --- \\
\hline & Itapuranga & 2015 & NP & --- & --- \\
\hline & Palmeiras & 2015 & NP & --- & --- \\
\hline & Porangatu & 2015 & NP & --- & --- \\
\hline & Quirinópolis & 2015 & NP & --- & --- \\
\hline $\begin{array}{l}\text { Universidade Federal de Catalão } \\
\text { (UFCat) }\end{array}$ & Catalão & ND & --- & --- & --- \\
\hline $\begin{array}{l}\text { Universidade Federal de Goiás } \\
\text { (UFG) }\end{array}$ & Goiânia & 2015 & $\begin{array}{c}\text { Educação em Ciências na } \\
\text { Educação de Jovens e Adultos }\end{array}$ & 64 & Optativa \\
\hline $\begin{array}{l}\text { Universidade Federal de Jataí } \\
\text { (UFJ) }\end{array}$ & Jataí & 2015 & $\mathrm{NP}$ & --- & --- \\
\hline
\end{tabular}

Quadro 1 - Relação entre os cursos de Licenciatura em Ciências Biológicas em IES públicas do estado de Goiás e a oferta de componentes curriculares da EJA. MC - Matriz Curricular; $\mathrm{CH}$ - Carga Horária; ND - Não disponibiliza no site da instituição; NP - Não possui o componente curricular no PPC. *O

Campus Avançado de Catalão oferece o curso de Licenciatura em Ciências Naturais, que abarca Biologia, Física e Química. **A UEG disponibiliza apenas as matrizes curriculares dos cursos em seu site oficial.

Fonte: elaboração dos autores.

Paranhos e Firmino (2013) indicam elementos a serem considerados na formação de professores de Biologia para que estes exerçam suas atividades profissionais na modalidade EJA. Essa formação envolve a discussão sobre: a) os sujeitos da EJA (educando, educador, gestores); b) a concepção de educação como direito; c) a relação dos educandos com os conhecimentos biológicos; d) relação teoria e prática; universidade e escola da educação básica (FIGURA 1). 


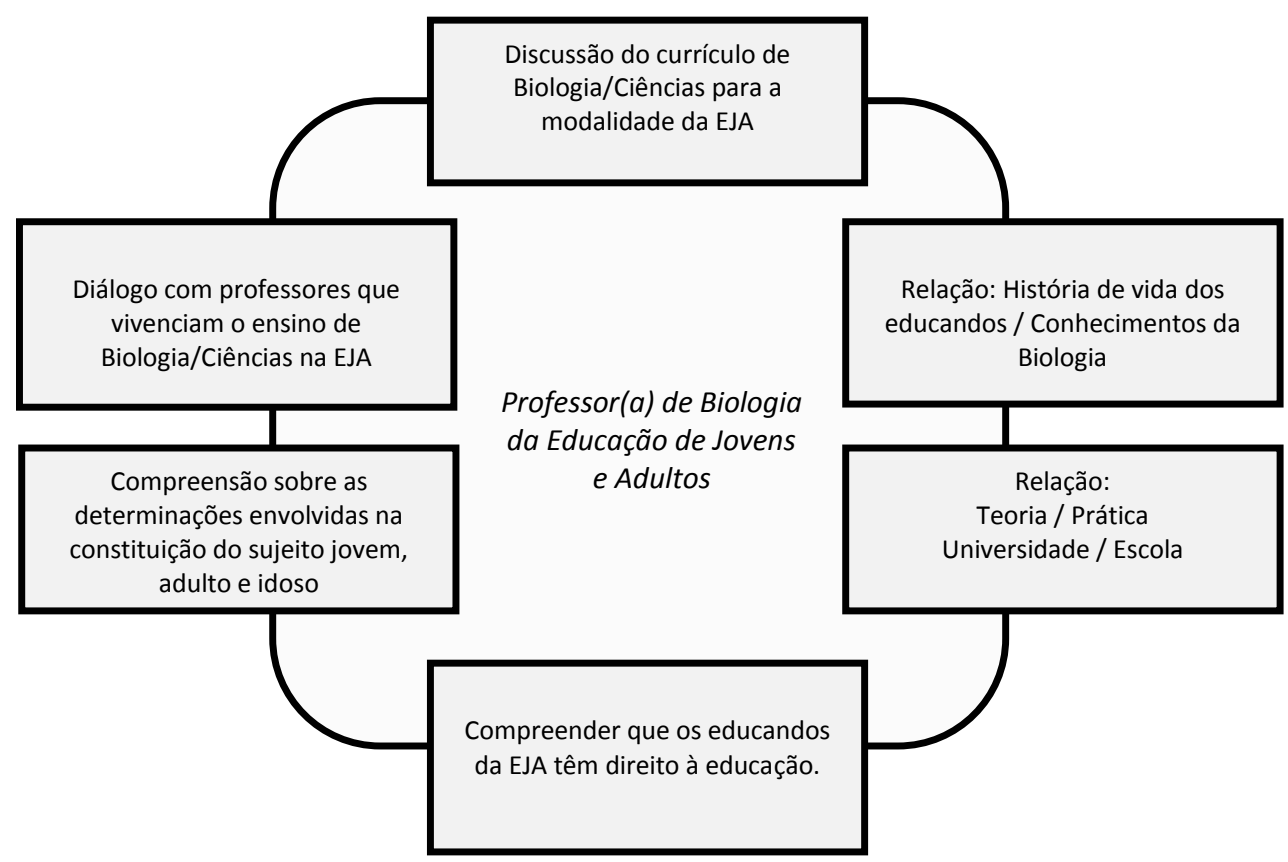

Figura 1 - Necessidades formativas do professor de Biologia para atuar na EJA Fonte: adaptado de Paranhos e Firmino (2013).

Face à demanda de formação de professores para a EJA e, especificamente, aos desafios enfrentados pela formação de professores de Biologia, durante o processo de reformulação do Projeto Pedagógico de Curso (PPC) das Ciências Biológicas - Licenciatura (Instituto de Ciências Biológicas - Universidade Federal de Goiás), foi criada a disciplina Educação em Ciências na Educação de Jovens e Adultos.

O presente artigo objetiva relatar a experiência que envolveu o processo de formulação do componente curricular EJA, trazendo para isso uma descrição do contexto que envolveu esse processo. Objetiva, também, relatar a experiência do primeiro oferecimento da disciplina ao curso, ou seja, a implementação do componente, com destaque para aspectos do planejamento e da realização de atividades durante o oferecimento da matéria. Com esses objetivos, espera-se que o texto possa fomentar a discussão da EJA nos cursos de licenciatura e o desenvolvimento de pesquisas que tomem a relação EJA - formação de professores como objeto de investigação.

\section{ASPECTOS ESTRUTURAIS DO RELATO}

\section{O contexto de criação da disciplina de EJA}

O componente curricular ora relatado e discutido surgiu no momento da reformulação do Projeto Pedagógico de Curso (Ciências Biológicas - Licenciatura), o que envolveu as 
atividades coordenadas pelo Núcleo Docente Estruturante ${ }^{8}$ (NDE). Nesse processo houve a participação de representantes dos diferentes departamentos do Instituto de Ciências Biológicas da Universidade Federal de Goiás (Bioquímica e Biologia Molecular, Botânica, Ecologia, Educação em Ciências, Farmacologia, Ciências Fisiológicas, Genética, Histologia e Embriologia e Morfologia) e a participação do centro acadêmico do curso.

O PPC vigente (UFG, 2017) é uma proposta formativa construída coletivamente após um acumulado de discussões sobre a formação de professores de Biologia em que os principais traços são: a) a abordagem da história e filosofia da ciência para a discussão dos conceitos científicos das Ciências Biológicas; b) a construção e fortalecimento da identidade profissional docente; c) a escola pública brasileira como o ponto de partida e de chegada para a formação e exercício profissional dos professores de Biologia.

No sentido de marcar a identidade profissional dos egressos (professor de Biologia), foi uma opção, quando da formulação do PPC em questão, não atender a carga horária mínima de conteúdos biológicos preconizada pelo Conselho Federal de Biologia (CFBio) de 3.200 horas de Componentes Curriculares de Ciências Biológicas (BRASIL, 2012). O NDE considerou para a construção do PPC o documento das Diretrizes Nacionais de Formação de Professores que preconiza carga horária mínima total 3.200 horas, o que inclui, no caso da Licenciatura em Ciências Biológicas, disciplinas do conhecimento biológico e pedagógico.

A carga horária do curso é atualmente de 3.416 horas, divididas em: a) 33 disciplinas obrigatórias do núcleo comum: $1.920 \mathrm{~h}$; b) 12 disciplinas obrigatórias do núcleo específico: 1.040h; c) disciplinas do núcleo específico optativo: 128h; d) disciplinas do núcleo livre: 128h; e) atividades complementares: 200h. Cabe salientar que o PPC do curso oferece 62 disciplinas de núcleo específico optativo (3.392h), dentre as quais os alunos devem cursar 128h. Além disso, a coordenação do curso deve garantir o oferecimento de cada componente por pelo menos uma vez a cada dois anos.

A formulação do componente curricular de EJA deu-se no âmbito do Departamento de Educação em Ciências, a partir do acumulado de pesquisas realizadas por professores do próprio departamento (MURÇA et al., 2013; PARANHOS, 2009; PARANHOS; FIRMINO, 2013; PARANHOS; SHUVARTZ, 2013; SANTOS, 2015) e dos marcos teóricos que tomaram para análise o problema da formação docente para tal modalidade. Há de se destacar que o PPC anterior, que vigorou entre os anos de 2006 e 2014, não continha em sua proposta nenhum componente que contemplasse a discussão da EJA.

\footnotetext{
${ }^{8}$ O NDE é constituído por um grupo de docentes diretamente ligados aos cursos de graduação que possui como atribuições acadêmicas a concepção, implementação, acompanhamento e atualização do Projeto Pedagógico de Curso (PPC).
} 
A disciplina de EJA constitui o núcleo específico da matriz curricular e possui natureza optativa, sendo que seu oferecimento deve ocorrer pelo menos uma vez a cada dois anos. Mesmo que com essa natureza, nos sentimos autorizados a afirmar que houve uma ruptura em que o elemento EJA foi inserido na formação do(a) professor(a) de Biologia, já que a modalidade possivelmente fará parte do campo de exercício profissional. O componente curricular apresenta a seguinte ementa:

Histórico e dimensão política da Educação de Jovens e Adultos no Brasil. Os sujeitos da Educação de Jovens e Adultos. Relação entre a Educação em Ciências e a Educação de Jovens e Adultos. Análise das propostas oficiais (Federal, Estadual e Municipal) para o Ensino de Ciências na Educação de Jovens e Adultos (UFG, 2017, p. 38).

Pelos elementos da ementa, a disciplina demarca a intencionalidade de proporcionar à formação inicial de professores de Biologia uma discussão que prima pela trajetória histórica da EJA para compreender as determinações envolvidas na necessidade de escolarizar jovens, adultos e idosos no Brasil. E, a partir disso, tem-se a compreensão das possibilidades de atuação profissional ao ensinar Ciências/Biologia na modalidade.

\section{O contexto de implementação do componente Educação em Ciências na EJA}

O PPC reformulado entrou em vigência em 2015, e a disciplina de EJA foi oferecida pela primeira vez no primeiro semestre de 2017 para alunos do curso de Ciências Biológicas Licenciatura do período integral. Cabe salientar que a disciplina, além de ser optativa para o curso em questão, é um componente de Núcleo Livre ${ }^{9}$ para todos os cursos da Universidade. Ou seja, a depender do número de vagas disponíveis, qualquer discente poderia se matricular na disciplina. Os professores responsáveis pela criação do componente pensaram nessa possibilidade para garantir que outras licenciaturas das Ciências da Natureza (Química e Física) pudessem ter contato com a discussão sobre a EJA. A disciplina contou com quatorze alunos(as) matriculados, mas concluíram-na oito discentes dos seguintes cursos: a) Ciências Biológicas - Licenciatura (06); b) Química - Licenciatura (01); c) Comunicação Social - Bacharelado (01). O trabalho desenvolvido na disciplina foi dividido em três unidades (QUADRO 2).

\footnotetext{
${ }^{9}$ De acordo com o Regulamento Geral dos Cursos de Graduação da Universidade, um “Núcleo Livre (NL) é o conjunto de conteúdos que têm por objetivo: I- ampliar e diversificar a formação do estudante; II- promover a interdisciplinaridade e a transdisciplinaridade; III- possibilitar o aprofundamento de estudo em áreas de interesse do estudante; IV- viabilizar o intercâmbio entre estudantes de diferentes cursos da UFG" (UFG, 2019).
} 


\begin{tabular}{|c|c|}
\hline Unidades Didáticas & Objetivos \\
\hline $\begin{array}{c}\text { Unidade I } \\
\text { Histórico da educação de } \\
\text { adultos e aspectos políticos }\end{array}$ & $\begin{array}{c}\text { Compreender a trajetória histórica e política da EJA no Brasil para } \\
\text { identificar e analisar os elementos de permanência e rupturas dessa } \\
\text { trajetória quanto ao projeto formativo da educação de adultos. }\end{array}$ \\
\hline $\begin{array}{c}\text { Unidade II } \\
\text { Ciêneitos da EJA / Ensino de }\end{array}$ & $\begin{array}{c}\text { Apresentar e discutir as especificidades da EJA a partir dos sujeitos } \\
\text { (educando, educador e gestores) da modalidade. }\end{array}$ \\
\hline $\begin{array}{c}\text { Unidade III } \\
\text { O conhecimento científico }\end{array}$ & $\begin{array}{c}\text { Analisar e discutir a relação Educação em Ciências/EJA na produção } \\
\text { científica para avaliar como essa produção tem entendido a } \\
\text { necessidade histórica da educação de adultos e como os diferentes } \\
\text { elementos da Educação em Ciências têm sido tomados como objeto } \\
\text { na EJA pesquisa. }\end{array}$ \\
\hline
\end{tabular}

Quadro 2 - Unidades didáticas e objetivos formativos da disciplina de EJA Fonte: elaboração dos autores.

Todas as unidades continham textos para fundamentar as discussões realizadas em sala de aula, tendo em vista os objetivos traçados para cada uma delas. É salutar demarcar que, para atingir esses objetivos, foi necessário subdividir as unidades em temas e, para isso, cada tema possuía um texto para leitura básica (obrigatória) e outro para leitura complementar (opcional).

A Unidade I foi subdividida em três eixos de discussão (aspectos históricos e políticos e políticas públicas). Defendemos um exercício profissional do(a) professor(a) de Biologia na EJA que seja fundamentado numa sólida relação entre os conhecimentos da ciência de base (Biologia) com os conhecimentos da educação, aqui, aqueles ligados à EJA. Pode-se considerar que a educação de adultos possui uma longa trajetória histórica que remonta os tempos da educação jesuítica e se desenvolveu ao longo do decurso histórico da educação brasileira, sempre atrelada aos diferentes interesses político-formativos. Soma-se a isso, a necessidade do(a) professor(a) de Biologia em formação inicial compreender a EJA como pauta de luta de um movimento social (Fórum Brasileiro de EJA), já que parte das políticas públicas dessa modalidade se desdobrou do debate da sociedade civil com o Estado. Atualmente, os contextos de desmonte da EJA (financiamento, o lugar da educação de adultos no MEC, concepções de EJA) no país têm acirrado os debates sobre a modalidade. Os textos de Dantas (2009), Haddad e Di Pierro (2000), Machado (1997), Machado (2009), Machado e Rodrigues (2014) e Ventura (2013) fundamentaram as atividades da unidade, desenvolvidas em cinco encontros (20h).

A Unidade II contou com cinco eixos de discussão: i) educando; ii) educadores; iii) ensino de Ciências na EJA (projeto formativo); iv) currículo e ensino de Ciências na EJA; v) propostas curriculares da Secretaria Estadual de Educação (Goiás) e da Secretaria Municipal de Educação (Goiânia). A prática pedagógica do(a) professor(a) de Biologia será endereçada a 
um público (adolescente, jovem, adulto e idoso) que, por motivos diversos, não iniciou a trajetória escolar e/ou a teve interrompida. Em nossa leitura, o público da EJA é o traço mais determinante e caracterizador da especificidade da modalidade educativa, e, sendo assim, foi proporcionado aos(as) alunos(as) da disciplina um diálogo aberto com um educando da EJA. O educando relatou aspectos da sua história de vida, enfatizando os motivos de afastamento da escola e os que o fizeram retornar a ela.

Professoras da EJA também foram convidadas para dialogar com os(as) alunos(as) da disciplina. Na ocasião, as educadoras destacaram aspectos da prática pedagógica propriamente dita, tendo em vista o público da modalidade e a apropriação dos conceitos científicos das diferentes áreas do conhecimento. Quanto a isso, foi enfatizada a necessidade do desenvolvimento de um compromisso político-pedagógico com o ensino dos diferentes conhecimentos ao público da EJA. Durante o diálogo, as educadoras destacaram a relevância de o curso de Ciências Biológicas - Licenciatura conter uma disciplina que contempla a discussão da educação de adultos, pois alegaram que, na época em que fizeram a graduação (História e Letras - Português), essa discussão não existia na formação inicial.

Há uma compreensão bem sedimentada no campo da Educação de Jovens e Adultos de que o ensino dos componentes curriculares deve partir do cotidiano dos educandos. Enfatizamos que essa compreensão necessita ser revisitada de modo a entender essa "partida", pois a prática social dos educandos deve ser o ponto de partida e de chegada do ensino de Biologia para os jovens, adultos e idosos. Noutras palavras, o conhecimento biológico ensinado deve proporcionar aos alunos da EJA a ampliação da leitura da realidade, bem como as possibilidades de intervir nela. Do contrário, se as atividades de ensino desenvolvidas na escola coincidirem com o que os alunos já sabem, entendemos que o processo de marginalização reiterada e institucionalizada se instala (PARANHOS; CARNEIRO, 2019). Essas ideias fundamentaram as discussões sobre o currículo de Ciências na EJA, bem como o diálogo com representantes da secretaria estadual (Goiás) e municipal (Goiânia) de Educação quando apresentaram as propostas curriculares para EJA. Foram utilizadas as produções de Arroyo (2007), Costa e Echeverría (2013), Machado (2008), Oliveira (2005), Paranhos (2016), Vilanova e Martins (2008) e Young (2007) para orientar as discussões e atividades da Unidade II, realizadas em cinco encontros (20h).

A Unidade III foi destinada a uma análise de dissertações que se ocuparam em pesquisar o ensino de Ciências na EJA. Para isso, os estudantes de graduação foram divididos em grupos e foi disponibilizado a esses grupos um conjunto de quatorze dissertações para que pudessem ler e, a partir disso, organizar seminários. A organização dos seminários deveria contemplar os seguintes temas: a) questões e objetivos de pesquisa; b) concepções de EJA; c) o papel da educação escolar; d) os sujeitos da EJA e suas demandas formativas; v) o ensino de Ciências na EJA (projeto formativo). Os seminários foram realizados a partir da 
elaboração prévia de textos que continham sínteses analíticas sobre os temas e da discussão realizada em sala de aula. As pesquisas de Santos (2015), R. Costa (2012), Bertoglio (2013) e L. Costa (2010) foram analisadas pelos alunos da disciplina. Os seminários foram realizados em quatro encontros (16h).

A avaliação foi processual e contínua, pois envolveu a realização de diferentes atividades ao longo da disciplina e considerou: a apropriação dos conceitos apresentados pelos textos; o desenvolvimento da leitura e da escrita; formulação de questões sobre os textos lidos; capacidade de apresentar e articular ideias durante os debates; o desenvolvimento de textos autorais sobre o tema ensino de Ciências na EJA (análise de dissertações) (QUADRO 3).

\begin{tabular}{|c|c|}
\hline Instrumentos & Descrição \\
\hline Problematizações & $\begin{array}{c}\text { Os alunos deveriam encaminhar ao professor duas questões de cada texto } \\
\text { lido (leitura básica). Essas questões guiaram o professor no processo de } \\
\text { planejamento de aula, já que os estudantes deveriam enviar as perguntas } \\
\text { com antecedência. }\end{array}$ \\
\hline $\begin{array}{l}\text { Participação nas } \\
\text { Discussões }\end{array}$ & $\begin{array}{l}\text { As aulas expositivas dialogadas, necessariamente, demandam a participação } \\
\text { efetiva dos estudantes, portanto, esse foi um critério de avaliação. A } \\
\text { participação não deveria ser livresca e deveria estar muito afinada com as } \\
\text { discussões propostas a partir das leituras. }\end{array}$ \\
\hline Avaliação Escrita & $\begin{array}{c}\text { Esse instrumento objetiva avaliar a apropriação dos temas/conceitos via } \\
\text { elaboração de texto para articular as principais ideias discutidas na Unidade I. }\end{array}$ \\
\hline $\begin{array}{l}\text { Elaboração de texto } \\
\text { para o seminário }\end{array}$ & $\begin{array}{c}\text { Os estudantes deveriam elaborar um texto síntese para problematizar a } \\
\text { discussão em concordância com os temas propostos. As problematizações } \\
\text { deveriam ter como ponto de partida as discussões e referências bibliográficas } \\
\text { utilizadas na disciplina. }\end{array}$ \\
\hline Seminário & $\begin{array}{l}\text { Apresentação do texto previamente elaborado para problematizar e discutir } \\
\text { junto aos colegas e professores os temas determinados. }\end{array}$ \\
\hline
\end{tabular}

Quadro 3 - Processo de avaliação empregado na disciplina de EJA Fonte: elaboração dos autores.

Especificamente sobre a avaliação escrita, foi proposta aos alunos a elaboração de um texto analítico a partir da observação de duas imagens (FIGURA 2). 

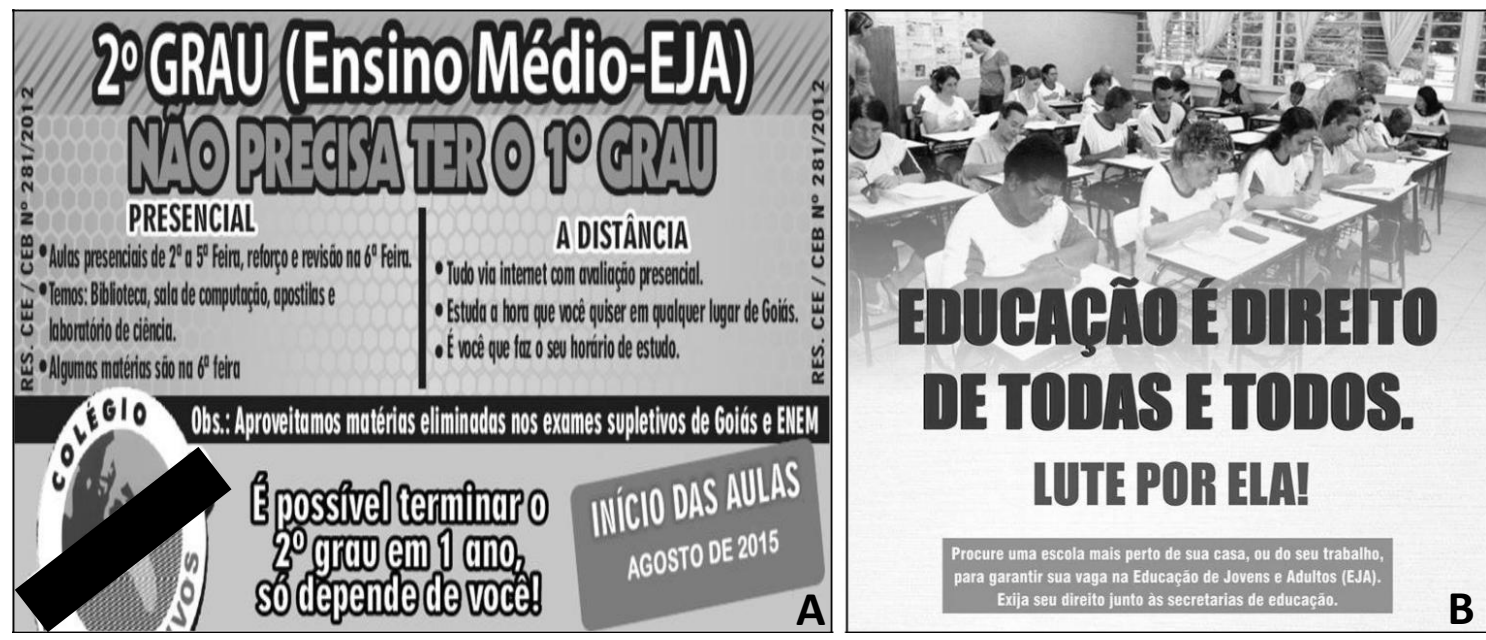

Figura 2 - Imagens utilizadas na avaliação escrita da disciplina de EJA.

Fonte: Imagem A - campanha publicitária destinada ao público da cidade de Goiânia; Imagem B cartaz elaborado pelo Fórum Goiano de EJA divulgado em terminais e ônibus do transporte coletivo da cidade de Goiânia para divulgar a EJA e telefones para realização de matrículas.

A escrita da análise deveria considerar as ideias contidas nos textos da Unidade I (Dantas (2009), Haddad e Di-Pierro (2000), Machado (1997), Machado (2009), Machado e Rodrigues (2014) e Ventura (2013)) e as discussões realizadas em sala de aula, para que os alunos pudessem estabelecer um paralelo crítico sobre as concepções de Educação de Jovens e Adultos presentes nas imagens A e B da Figura 2.

Tendo em vista que a disciplina foi oferecida pela primeira vez ao curso, foi elaborado um instrumento para avaliar o componente curricular, que considerou: a) motivos de escolha da disciplina pelos estudantes; b) pontos fortes e frágeis; c) contribuições da discussão para a formação profissional. A respeito dos motivos de escolha da disciplina, os estudantes relataram a importância desta no contexto da formação de professores, o nome do componente curricular e o prestígio do professor no campo de estudo como um chamariz para a inscrição, além da necessidade de compreender os aspectos que caracterizam outras modalidades da educação básica.

Quando perguntados(as) sobre os aspectos fortes da disciplina, os(as) educandos(as) avultaram as potencialidades que o componente curricular tem de criar momentos formativos relevantes para um docente. O contato com os sujeitos da EJA, a leitura, análise e sínteses das produções que versam sobre o ensino de Ciências na área e, principalmente, o nascimento de um compromisso político com a modalidade caracterizam os elementos sinalizados pelos(as) discentes, os quais se constituem enquanto canais para a construção da práxis pedagógica daqueles(as) professores(as) em formação.

Quanto aos aspectos frágeis da disciplina os(as) estudantes demarcaram a necessidade de rever organização do seminário a partir da leitura e análise de dissertações. De acordo com 
eles(as), há de se pensar na maturidade acadêmica dos(as) alunos(as) de graduação para compreender a estruturação de uma pesquisa e a sua escrita no formato de dissertação. Soma-se, a isso, o curto tempo destinado à leitura e análise das produções.

Por fim, quando questionados(as) a respeito das contribuições da disciplina, os discentes apresentaram o seu papel, na ressignificação de suas compreensões acerca da modalidade. Eles assinalaram a relevância que as discussões tiveram para a reelaboração do seu entendimento, no que tange às marcas e elementos de permanência que historicamente atravessam a EJA.

\section{CONSIDERAÇÕES FINAIS}

Discutir a Educação de Jovens e Adultos na sua relação com o ensino de Ciências permite, aos sujeitos envolvidos no processo, o delineamento de novos olhares a respeito da docência na modalidade e da organização dos conteúdos e abordagens da ciência de referência (Biologia/Ciências da Natureza). Não se trata de apresentar nenhum manual "catequético" de metodologias para o ensino de Ciências na EJA, mas sim de evidenciar os traços distintivos que a caracterizam, já que, historicamente, esta tem sido refém das centralidades metodológicas, adaptações, transitoriedades e concepções de formação aligeirada atrelada à educação escolar.

Sobre o trabalho pedagógico desenvolvido na disciplina, esse oportunizou o contato dos futuros professores com a modalidade, seus sujeitos (professores e educandos) e seus desafios na sociedade contemporânea. As atividades formativas, ao considerarem a problematização da realidade atual da EJA no país, oportunizaram momentos de avaliação nos quais os sujeitos puderam analisar/reinterpretar essa realidade a partir de outras bases (conhecimento científico), o que possibilita uma atuação nessa realidade para sua superação.

Compreender a lógica dessa modalidade enquanto um produto de contradições e lutas pautadas por diferentes interesses de escolarização dá subsídios para que o professor em formação inicial perceba o seu movimento de constituição e especificidades e estabeleça o compromisso político com uma educação que tenha no horizonte a apropriação dos conhecimentos científicos. Nesse sentido, há a necessidade de mais debates e da inclusão de mais disciplinas de EJA nos cursos de formação de professores de Ciências, em especial aquelas que tenham como foco o ensino de Ciências na sua relação com a modalidade. Espera-se que este relato motive o desenvolvimento de outras experiências em cursos de formação de professores de Ciências/Biologia. 


\section{REFERÊNCIAS}

ALVES, Thiago et al. Jovens e adultos não escolarizados: uma multidão de invisíveis. In: OLIVEIRA, Edna Casto et al. (org.). Educação de jovens e adultos: trabalho e formação humana. São Carlos: Pedro \& João Editores, 2014. p. 167-190.

ARROYO, Miguel. Balanço da EJA: o que mudou nos modos de vida dos jovens-adultos populares? REVEJ@-Revista de Educação de Jovens e Adultos, Belo Horizonte, v. 1, n. 0, p. 5-19, ago. 2007.

BERTOGLIO, Diana Schuch. Estratégias pedagógicas para o ensino de ciências na EJA incluindo atividades em um museu interativo. 2013. Dissertação (Mestrado em Educação em Ciências e Matemática) - Pontifícia Universidade Católica do Rio Grande do Sul, Porto Alegre, 2013.

BRASIL. Lei de Diretrizes e Bases da Educação Nacional, LDB. 9394/1996, de 20 de dezembro de 1996. Estabelece as diretrizes e bases da educação nacional. Diário Oficial [da] República Federativa do Brasil, Brasília, DF. 23 dez. 1996.

BRASIL, Conselho Nacional de Educação. Parecer CNE/CEB 11/2000, de 9 de junho de 2000. Diretrizes Curriculares Nacionais para a Educação de Jovens e Adultos. Diário Oficial [da] República Federativa do Brasil, Brasília, DF. 9 jun. 2000.

BRASIL, Conselho Nacional de Educação. Resolução CNE/CP n. 1/2002, de 18 de fevereiro de 2002. Institui Diretrizes Curriculares Nacionais para a Formação de Professores da Educação Básica, em nível superior, curso de licenciatura, de graduação plena. Diário Oficial [da] República Federativa do Brasil, Brasília, DF. 19 fev. 2002.

BRASIL, Conselho Nacional de Educação. Resolução CNE/CP n. 02/2015, de 10 de julho de 2015. Define as Diretrizes Curriculares Nacionais para a formação inicial em nível superior (cursos de licenciatura, cursos de formação pedagógica para graduados e cursos de segunda licenciatura) e para a formação continuada. Diário Oficial [da] República Federativa do Brasil, Brasília, DF. 02 jul. 2015.

BRASIL, Conselho Nacional de Educação. Resolução CNE/CP n. 02/2019, de 20 de dezembro de 2019. Define as Diretrizes Curriculares Nacionais para a Formação Inicial de Professores para a Educação Básica e institui a Base Nacional Comum para a Formação Inicial de Professores da Educação Básica (BNC-Formação). Diário Oficial [da] República Federativa do Brasil, Brasília, DF. 10 fev. 2020.

COSTA, Lorenna Silva Oliveira. Análise da elaboração conceitual nos processos de ensinoaprendizagem em aulas de química para jovens e adultos: por uma formação integrada. 2010. Dissertação (Mestrado em Educação em Ciências e Matemática) - Universidade Federal de Goiás, Goiânia, 2010.

COSTA, Lorenna Silva Oliveira; ECHEVERRÍA, Agustina Rosa. Contribuições da teoria sóciohistórica para a pesquisa sobre a escolarização de jovens e adultos. Ciência \& Educação, 
Bauru, v. 19, n. 2, p. 339-357, 2013. DOI: http://dx.doi.org/10.1590/S151673132013000200008

COSTA, Rita Mara Reis. Conversando nas aulas de ciências: um diálogo entre educomunicação e abordagem temática na EJA. 2012. Dissertação (Mestrado em Ensino de Ciências) - Universidade de Brasília, Brasília, 2012.

DANTAS, Aline Cristina. Fóruns de EJA: mobilização na luta pelo direito à educação de jovens e adultos. In: Anais do 17ํ Congresso de Leitura do Brasil. Campinas: ALB, 2009, p. 45.

HADDAD, Sérgio; DI PIERRO, Maria Clara. Escolarização de jovens e adultos. Revista Brasileira de Educação, Rio de Janeiro, n. 14, p. 108-130, mai. /ago. 2000. DOI: https://doi.org/10.1590/S1413-24782000000200007

HADDAD, Sérgio; SIQUEIRA, Filomena. Analfabetos entre os jovens e adultos no Brasil. Revista Brasileira de Alfabetização, Florianópolis, v. 1, n. 2, p. 88-110, 2016. DOI: https://doi.org/10.47249/rba.2015.v1.81

MACHADO, Maria Margarida. Política Educacional para Jovens e Adultos: a experiência do PROJETO AJA (93/96) na Secretaria Municipal da Educação de Goiânia. 1997. Dissertação (Mestrado em Educação Escolar Brasileira) - Faculdade de Educação, Universidade Federal de Goiás, Goiânia, 1997.

MACHADO, Maria Margarida. Formação de professores para EJA: uma perspectiva de mudança. Revista Retratos da Escola, Brasília, v. 2, n. 2-3, p. 161-174, jan./dez. 2008. DOI: https://doi.org/10.22420/rde.v2i2/3.133

MACHADO, Maria Margarida. A educação de jovens e adultos no Brasil pós-Lei no 9.394/96: a possibilidade de constituir-se como política pública. Em Aberto, Brasília, v. 22, n. 82, p. 1739, nov. 2009. DOI: http://dx.doi.org/10.24109/2176-6673.emaberto.22i82.\%25p

MACHADO, Maria Margarida; RODRIGUES, Maria Emília de Castro. A EJA na próxima década e a prática pedagógica do docente. Revista Retratos da Escola, Brasília, v. 8, n. 15, p. 383395, jul./dez. 2014. DOI: https://doi.org/10.22420/rde.v8i15.448

MOTA, Diego. Formação de professores de Educação Física para atuar na educação de jovens e adultos. 2019. Trabalho de conclusão de curso (Graduação) - Universidade Federal Rural de Pernambuco, Recife, 2019.

MURÇA, Jenyffer Soares Estival et al. As licenciaturas em Ciências Biológicas no estado de Goiás: silêncios que perpassam o perfil profissional do professor para a educação de jovens e adultos. In: V Encontro Estadual de Didática e Prática de Ensino, Goiânia 2013.

OLIVEIRA, Marta Kohl. Jovens e Adultos como sujeitos de conhecimento e aprendizagem. In: BRASIL. Educação como exercício de diversidade. Brasília: UNESCO, MEC, ANPEd, 2005. p. 6184. 
PAIVA, Jane. Imaginando uma EJA que atenda a demandas de cidadania, equidade, inclusão e diversidade. Currículo sem Fronteiras, Uberlândia, v. 19, n. 3, p. 1142-1158, set./dez. 2019. DOI: http://dx.doi.org/10.35786/1645-1384.v19.n3.20

PEREIRA, Marsílvio Gonçalves; OLIVEIRA, Júlio César Rufino Ramos; FERREIRA, Thiago dos Santos. Análise da pesquisa em educação em ciências e ensino de biologia sobre educação de jovens e adultos (EJA) em periódicos brasileiros. Revista Insignare Scientia, Cerro Largo, v. 2, n. 2, p. 100-114, 16 set. 2019. DOI: https://doi.org/10.36661/2595-4520.2019v2i2.10817

PARANHOS, Rones de Deus. A relação entre a educação ambiental e a educação de jovens $e$ adultos. 2009. Dissertação (Mestrado em Educação em Ciências e Matemática) - PróReitoria de Pós-Graduação, Universidade Federal de Goiás, Goiânia, 2009.

PARANHOS, Rones de Deus. O ensino de ciências na educação de jovens e adultos: uma análise sob o viés da pedagogia histórico-crítica. In: PIRES, Luciene de Assis; SOUZA, Marta João Francisco Silva; DIOGO, Rodrigo Claudino. Ensino de ciências e matemática: do mundo das ideias à sala de aula. Goiânia: Editora IFG, 2016. p. 59-70.

PARANHOS, Rones de Deus. Ensino de Biologia na educação de jovens e adultos: o pensamento político-pedagógico da produção científica brasileira. 2017. Tese (Doutorado em Educação) - Faculdade de Educação, Universidade de Brasília, Brasília, 2017.

PARANHOS, Rones de Deus; CARNEIRO, Maria Helena da Silva. Ensino de Biologia para a educação de jovens e adultos: desafios para uma formação que proporcione o desenvolvimento humano. Revista EJA em Debate, Florianópolis, v. 8, n. 14, p. 1-24, 2019.

PARANHOS, Rones de Deus; FIRMINO, Simone Gomes. Professor, onde eu encontro células no meu corpo? - as necessidades formativas do professor para atuar na EJA. In:

GUIMARÃES, Simone Sendin Moreira; PARANHOS, Rones de Deus; SILVA, Karolina Martins Almeida. A formação de professores de Biologia: dos desa(fios) da trama. São Carlos: Pedro \& João Editores, 2013. p. 87-105.

PARANHOS, Rones de Deus; SHUVARTZ, Marilda. A relação entre a educação ambiental e a educação de jovens e adultos sob a perspectiva da trajetória dos educadores. Contexto \& Educação, Unijuí, v. 28, n. 91, p. 84-105, 2013. DOI: https://doi.org/10.21527/21791309.2013.91.84-105.

SANTOS, Sayonara Martins. O diálogo como estratégia na formação inicial de professores de Ciências/Biologia. 2015. Dissertação (Mestrado em Educação em Ciências e Matemática) Universidade Federal de Goiás, Goiânia, 2015.

SAVIANI, Dermeval. Pedagogia Histórico-Crítica. 11. ed. Campinas: Autores Associados, 2013.

SOARES, Leôncio. A formação inicial do educador de jovens e adultos: um estudo da habilitação de EJA nos cursos de Pedagogia. In: XXVIII REUNIÃO DA ANPED. Caxambu, 2005. 
SOARES, Leôncio. Formação de educadores de jovens e adultos. Belo Horizonte: Autêntica/SECAD-MEC/UNESCO, 2006.

UNIVERSIDADE FEDERAL DE GOIÁS. Conselho de Ensino, Pesquisa, Extensão e Cultura. Resolução CEPEC no 1527 de 13 de julho de 2017. Aprova o Projeto Pedagógico do Curso de Graduação em Ciências Biológicas, grau acadêmico Licenciatura, modalidade presencial, do Instituto de Ciências Biológicas da Regional Goiânia, para os alunos ingressos a partir de 2015. Goiânia, 2017.

UNIVERSIDADE FEDERAL DE GOIÁS, RESOLUÇÃO - CEPEC no 1557R de 29 de novembro de 2019. Regulamento Geral dos Cursos de Graduação (RGCG) da Universidade Federal de Goiás. Goiânia, 2019.

VENTURA, Jaqueline. A EJA e os desafios da formação docente nas licenciaturas. Educação $e$ Contemporaneidade, Salvador, v. 21, n. 37, p. 71-82, jan./jun. 2012. DOI:

http://dx.doi.org/10.21879/faeeba2358-0194.2012.v21.n37.p\%25p

VENTURA, Jaqueline. Educação ao longo da vida e organismos internacionais: apontamentos para problematizar a função qualificadora da Educação de Jovens e Adultos. Revista Brasileira de Educação de Jovens e Adultos, Salvador, v. 1, n. 1, p. 29-44, 2013.

VENTURA, Jaqueline; BOMFIM, Maria Inês. Formação de professores e educação de jovens e adultos: o formal e o real nas licenciaturas. Educação em Revista, Belo Horizonte, v. 31, n. 2, p. 211-227, abr./ jun. 2015. DOI: https://doi.org/10.1590/0102-4698127011

VILANOVA, Rita; MARTINS, Isabel. Educação em Ciências e educação de jovens e adultos: pela necessidade do diálogo entre campos e práticas. Ciência \& Educação, Bauru, v. 14, n. 2, p. 331-346, 2008. DOI: https://doi.org/10.1590/S1516-73132008000200011.

VIÑAL-JR, José Veiga; MIRANDA, Helga Porto. Formação do professor para a educação de jovens e adultos: a importância do processo formativo na perspectiva emancipatória. Revista Cocar, Belém, v. 13, n. 27, p. 473-501, set./dez. 2019.

YOUNG, Michael. Para que servem as escolas? Educação e Sociedade, Campinas, v. 28, n. 101, p. 1287-1302, set./dez. 2007. DOI: https://doi.org/10.1590/S0101-73302007000400002 


\section{Rones de Deus Paranhos}

Doutor em Educação pela Faculdade de Educação da Universidade de Brasília. Professor do Departamento de Educação em Ciências, Instituto de Ciências Biológicas da Universidade Federal de Goiás (ICB/UFG). Professor do Programa de Pós-Graduação em Educação em Ciências e Matemática (PPGECM - UFG). Coordenador da Rede de Pesquisa em Ensino de Ciências na EJA (REPEC-EJA).

paranhos@ufg.br

\section{Lucas Martins de Avelar}

Licenciado em Ciências Biológicas pelo Instituto de Ciências Biológicas da Universidade Federal de Goiás. Discente do Programa de Pós-Graduação em Educação em Ciências e Matemática (PPGECM - UFG). Membro da Rede de Pesquisa em Ensino de Ciências na EJA (REPEC-EJA).

lucasmavelar@gmail.com

\section{Cristina da Costa Krewer Mascioli}

Doutora em Ciências Biológicas pela Universidade Federal de Santa Maria (UFSM). Professora do Departamento de Histologia e Embriologia, Instituto de Ciências Biológicas da Universidade Federal de Goiás (ICB/UFG). Membro da Rede de Pesquisa em Ensino de Ciências na EJA (REPEC-EJA).

criskrewer@ufg.br

\section{Simone Sendin Moreira Guimarães}

Doutora em Educação Escolar pela Universidade Estadual Paulista Júlio de Mesquita Filho UNESP (Campus Araraquara). Professora do Departamento de Educação em Ciências, Instituto de Ciências Biológicas da Universidade Federal de Goiás (ICB/UFG). Professor do Programa de Pós-Graduação em Educação em Ciências e Matemática (PPGECM - UFG). Coordenadora da Rede de Pesquisa em Ensino de Ciências na EJA (REPEC-EJA). sisendin@ufg.br 